\title{
Absolute coronary blood flow measurement and microvascular resistance in ST-elevation myocardial infarction in the acute and subacute phase
}

Citation for published version (APA):

Wijnbergen, I. F., van 't Veer, M., Lammers, J., Ubachs, J., \& Pijls, N. H. J. (2016). Absolute coronary blood flow measurement and microvascular resistance in ST-elevation myocardial infarction in the acute and subacute phase. Cardiovascular Revascularization Medicine, 17(2), 81-87. https://doi.org/10.1016/j.carrev.2015.12.013

DOI:

10.1016/j.carrev.2015.12.013

Document status and date:

Published: 17/03/2016

Document Version:

Publisher's PDF, also known as Version of Record (includes final page, issue and volume numbers)

Please check the document version of this publication:

- A submitted manuscript is the version of the article upon submission and before peer-review. There can be important differences between the submitted version and the official published version of record. People interested in the research are advised to contact the author for the final version of the publication, or visit the $\mathrm{DOI}$ to the publisher's website.

- The final author version and the galley proof are versions of the publication after peer review.

- The final published version features the final layout of the paper including the volume, issue and page numbers.

Link to publication

\footnotetext{
General rights

- You may freely distribute the URL identifying the publication in the public portal. follow below link for the End User Agreement:

www.tue.nl/taverne

Take down policy

If you believe that this document breaches copyright please contact us at:

openaccess@tue.nl

providing details and we will investigate your claim.
}

Copyright and moral rights for the publications made accessible in the public portal are retained by the authors and/or other copyright owners and it is a condition of accessing publications that users recognise and abide by the legal requirements associated with these rights.

- Users may download and print one copy of any publication from the public portal for the purpose of private study or research.

- You may not further distribute the material or use it for any profit-making activity or commercial gain

If the publication is distributed under the terms of Article $25 \mathrm{fa}$ of the Dutch Copyright Act, indicated by the "Taverne" license above, please 


\title{
Absolute coronary blood flow measurement and microvascular resistance in ST-elevation myocardial infarction in the acute and subacute phase ${ }^{\text {in }}$
}

\author{
Inge Wijnbergen ${ }^{\mathrm{a}, \mathrm{b}}$, Marcel van 't Veer ${ }^{\mathrm{a}, \mathrm{b}}$, Jeroen Lammers ${ }^{\mathrm{a}}$, Joey Ubachs ${ }^{\mathrm{a}}$, Nico H.J. Pijls ${ }^{\mathrm{a}, \mathrm{b}, *}$ \\ a Department of Cardiology, Catharina Hospital, Eindhoven, The Netherlands \\ b Department of Biomedical Engineering, Eindhoven University of Technology, Eindhoven, The Netherlands
}

\section{A R T I C L E I N F O}

\section{Article history:}

Received 17 August 2015

Received in revised form 7 December 2015

Accepted 22 December 2015

\section{Keywords:}

STEMI

Absolute flow

Microvascular dysfunction

\begin{abstract}
A B S T R A C T
Background/Purpose: In a number of patients with acute myocardial infarction (AMI), myocardial hypoperfusion, known as the no-reflow phenomenon, persists after primary percutaneous intervention (PPCI). The aim of this study was to evaluate the feasibility and safety of a new quantitative method of measuring absolute blood flow and resistance within the perfusion bed of an infarct-related artery. Furthermore, we sought to study noreflow by correlating these measurements to the index of microvascular resistance (IMR) and the area at risk (AR) as determined by cardiac magnetic resonance imaging (CMR).

Methods: Measurements of absolute flow and myocardial resistance were performed in 20 patients with STsegment elevation myocardial infarction (STEMI), first immediately following PPCI and then again after 3-5 days. These measurements used the technique of thermodilution during a continuous infusion of saline. Flow was expressed in $\mathrm{ml} / \mathrm{min}$ per gram of tissue within the area at risk.

Results: The average time needed for measurement of absolute flow, resistance and IMR was $20 \mathrm{~min}$, and all measurements could be performed without complication. A higher flow supplying the AR correlated with a lower IMR in the acute phase. Absolute flow increased from 3.14 to $3.68 \mathrm{ml} / \mathrm{min} / \mathrm{g}(\mathrm{p}=0.25)$ and absolute resistance decreased from 1317 to 1099 dyne.sec.cm-5/g $(\mathrm{p}=0.40)$ between the first day and fifth day after STEMI.

Conclusions: Measurement of absolute flow and microvascular resistance is safe and feasible in STEMI patients and may allow for a better understanding of microvascular (dys)function in the early phase of AMI.
\end{abstract}

(c) 2016 Elsevier Inc. All rights reserved.

\section{Introduction}

In acute myocardial infarction, early restoration of blood flow to the jeopardized myocardium is of paramount importance to limit infarct size and obtain a favorable long-term outcome. Primary percutaneous coronary intervention (PPCI) is the treatment of choice for reestablishing epicardial blood flow in patients with ST-segment elevation myocardial infarction (STEMI) [1,2]. Despite achievement of epicardial coronary artery reperfusion in approximately $90 \%$ of all patients, a number of these patients experiences persistent myocardial hypoperfusion due to moderate or severe microvascular dysfunction, also referred to as the "no-reflow" phenomenon [3-6]. In 1974, Kloner et al. described this phenomenon in dogs and showed that, after the temporary occlusion of a coronary artery, subendocardial perfusion defects were detectable and persistent after 90 min of occlusion [7]. Failure of reflow

\footnotetext{
it This study was supported by the "Friends of the Heart Foundation" (Stichting Vrienden van het Hart) in Eindhoven, The Netherlands.

* Corresponding author at: Department of Cardiology, Catharina Hospital Eindhoven, Michelangelolaan 2, 5623 EJ, Eindhoven, The Netherlands. Fax: + 31402447885.

E-mail address: nico.pijls@cze.nl (N.H.J. Pijls).
}

was associated with extensive capillary damage and myocardial cell swelling, leading to injury of the myocardial microvasculature.

The pathogenesis of no-reflow has not been elucidated completely and seems to be complex and multifactorial. Microvascular thromboembolism, spasm, intramyocardial edema and inflammatory responses of the myocardium with neutrophil plugging of the capillaries are all suggested to be responsible for this condition. It is well known that in patients in whom no or poor reflow occurs, prognosis is poor and more severe left ventricular dysfunction can be expected in comparison to those patients in whom microvascular reperfusion after PPCI is restored $[6,8]$. Therefore, knowledge about the actual state of the microvasculature and myocardial perfusion shortly after PPCI is important from a prognostic point of view.

Moreover, if microvascular reperfusion is still limited immediately after myocardial infarction, but recovers quickly in the days thereafter, it might be beneficial for long-term prognosis [8]. Lastly, knowledge about microvascular reperfusion in the acute phase might be important with respect to choice of adjunct mechanical or medical therapy, such as intra aortic balloon pumping (IABP), glycoprotein IIb/IIIa inhibitors or continuation of nitroglycerine. 
Assessment of microvascular perfusion and function has so far been difficult and hampered by a number of methodological and technical shortcomings. Furthermore, measurement of absolute blood flow in the infarcted area and true quantitative calculation of absolute resistance in acute MI has never been performed.

Recently, a new invasive technique for measuring absolute coronary blood flow and absolute myocardial resistance has been developed for patients with stable coronary disease [9]. This technique is based upon thermodilution using a continuous infusion of a low amount of saline through a microcatheter positioned selectively in a coronary artery. This technique is precise and not operator-dependent $[9,10]$. Measuring absolute blood flow and resistance has no meaning by itself as long as the distribution territory is unknown. Also, it is difficult to compare flow and resistance among territories, not to mention among patients. However, if the area of interest is the dependent myocardial territory of the occluded coronary artery, this technique makes it possible to compare absolute flow $(\mathrm{ml} / \mathrm{min})$ in STEMI patients between the moment immediately after epicardial reperfusion by PPCI and the recovery phase a few days later, with potential implications for treatment. Because the sensor measuring absolute blood flow by continuous infusion methodology simultaneously measures distal coronary pressure, absolute minimal resistance can be calculated in dyne.sec.cm-5, as shown before in experimental studies and in humans with stable coronary artery disease [9]. This quantitative measurement of flow and resistance is accurate and offers advantages over qualitative and indirect measures of resistance in STEMI, such as flow velocity-based indices or IMR $[11,12]$.

Consequently, the purpose of the present study was to evaluate the feasibility and safety of absolute blood flow measurement and resistance in STEMI patients, both in the acute and subacute phases. Furthermore, we aimed to correlate this method of flow measurement to IMR, the existing, non-quantitative, invasive standard method for detecting microvascular dysfunction.

\section{Material and methods}

\subsection{Patient selection and inclusion criteria}

STEMI patients $<75$ years of age admitted for PPCI with a total STsegment deviation of more than $10 \mathrm{~mm}$ were eligible if they presented within $12 \mathrm{~h}$ of symptom onset and had a culprit lesion in the proximal or mid segment of a coronary artery whose reference diameter was $\geq 3.0 \mathrm{~mm}$ by visual estimation. Patients with previous myocardial infarction in the culprit area or with previous bypass surgery were excluded. Other exclusion criteria were cardiogenic shock, inability to obtain femoral access to the arterial circulation, tortuous coronary arteries, complex or long-lasting PPCI, inability to understand and give informed consent, severe concomitant disease or conditions with a life expectancy of less than one year, other known myocardial diseases such as cardiomyopathy or left ventricular hypertrophy, and pregnancy.

Oral informed consent was obtained by the interventional cardiologist immediately after successful PPCI. A more extensive written informed consent was obtained after the procedure, either in the catheterization laboratory or in the coronary care unit. Twenty patients were permitted to be included by the institutional review board of the Catharina Hospital Eindhoven.

\section{2. $P P C I$ Procedure}

Patients received aspirin (300 mg) and a loading dose of clopidogrel, ticagrelor or prasugrel in the ambulance according to routine. Before angiography, all patients received heparin (5000 IU). Primary PCI was performed according to standard clinical practice. Use of thrombosuction or adjunctive pharmacology such as glycoprotein IIb/IIIa receptor inhibitors was left to the discretion of the operator. When, immediately following successful PPCI, the patient met the inclusion criteria and had given informed consent, measurements of distal coronary pressure and absolute coronary blood flow and resistance were performed as described below.

\subsection{Invasive hemodynamic measurements}

After successful PPCI of the culprit vessel, the guide wire was exchanged for one with distal pressure and temperature sensors (St Jude Medical, Minneapolis), whereafter distal coronary pressure, the index of microvascular resistance (IMR) and absolute flow were measured in the infarct-related artery as previously described in stable patients [9,10,12]. Maximal hyperemia, and thereby minimal microvascular resistance, was induced by using $140 \mu \mathrm{g} / \mathrm{kg} / \mathrm{min}$ of intravenous adenosine via a central venous catheter. Absolute minimal resistance was calculated by dividing distal pressure by the absolute flow and expressed in dyne.sec.cm- 5 per gram of tissue in the area at risk.

For determination of IMR, small bolus injections of $3 \mathrm{~cm}^{3}$ of saline were given into the infarct-related artery as described by Fearon et al. [12]. This was done three times at hyperemia. Mean transit time (Tmn) and Pd were measured simultaneously. IMR was calculated by multiplying the mean $\mathrm{P}_{\mathrm{d}}$ by the hyperaemic $\mathrm{T}_{\mathrm{mn}}$. IMR was taken as the average of the three consecutive measurements at hyperemia as described before [12].

\subsection{Measurement of absolute coronary blood flow}

Thereafter, absolute flow was measured. A small specially designed infusion catheter with four side holes in its most distal part was advanced over the pressure guide wire through the Y-connector. The tip of the infusion catheter was placed in the stent, i.e. at the level of the previous occlusion, and the sensor was placed in the distal part of the infarct related artery. The infusion catheter was then connected to an infusion pump by a second Y connector, enabling continuous infusion of saline at a rate of $20-30 \mathrm{ml} / \mathrm{min}$ (Fig. 1). The sensor-tipped guide wire was connected to the interface (Analyzer, St Jude Medical), and distal coronary pressure $\left(\mathrm{P}_{\mathrm{d}}\right)$ and temperature were displayed simultaneously. The exact infusion rate was chosen depending on the size of the artery and at the discretion of the operator. Next, a continuous recording was made of $\mathrm{P}_{\mathrm{d}}$ and distal blood temperature after complete mixing during constant saline infusion (Fig. 2). After a steady state had been achieved, the pressure/temperature sensor was pulled back into the infusion catheter so that the temperature of the saline $\left(T_{i}\right)$ at the location of the most proximal side hole could be measured (Fig. 2). Using the technology of continuous infusion of saline at a low rate, absolute hyperaemic blood flow $\left(\mathrm{Q}_{b}\right)$ can be calculated by the infusion rate of saline $\left(\mathrm{Q}_{i}\right)$, temperature of the infused saline $\left(\mathrm{T}_{i}\right)$ and distal blood temperature after complete mixing $(\mathrm{T})$, using the following equation:

$Q_{b}=1.08\left[\frac{T_{i}}{T}-1\right] Q_{i}+Q_{i} \approx 1.08\left[\frac{T_{i}}{T}\right] Q_{i}$

The factor 1.08 corrects for the differences in specific heat between blood and saline. The protocol of absolute flow measurement was performed again at hyperemia after an interval of $5 \mathrm{~min}$. The exact position of the sensor-tipped wire during measurements was documented on cine-angiography to make sure that the same position was chosen at the second exam 5 days later. All data were analyzed off line. Blood flow was expressed as $\mathrm{ml} / \mathrm{min}$ and by adding the area at risk from CMR, blood flow per gram of tissue was calculated in $\mathrm{ml} / \mathrm{min} / \mathrm{g}$ for the area at risk.

After three to five days, control angiography of the infarct-related artery was performed followed by measurements of FFR, IMR and absolute flow using exactly the same position of the wire and infusion catheter as in the first procedure. 


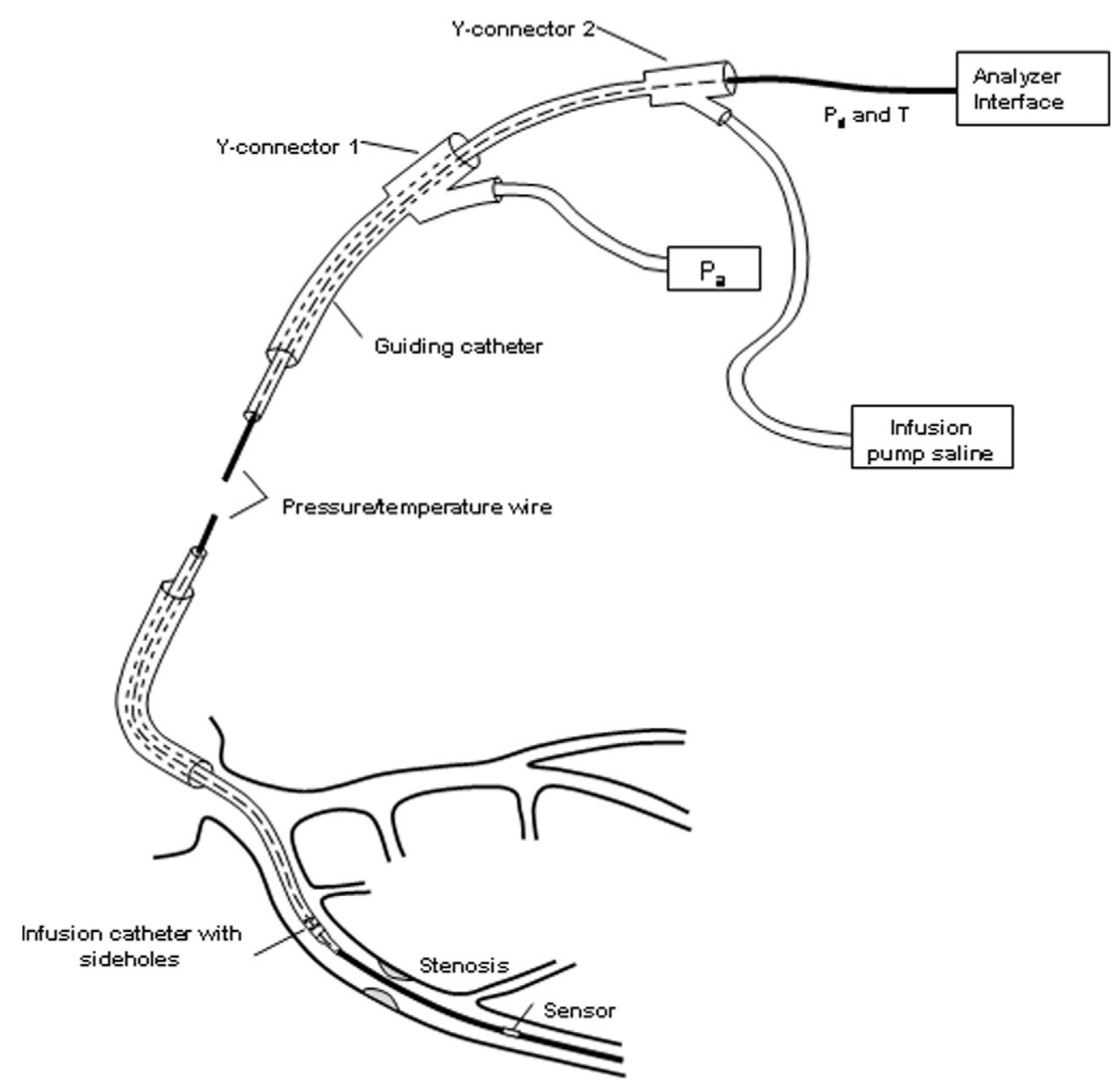

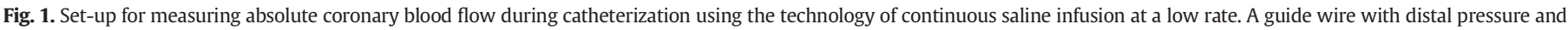

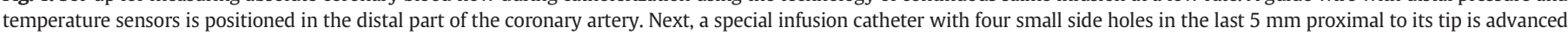

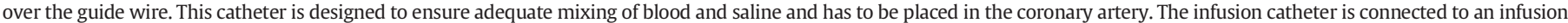

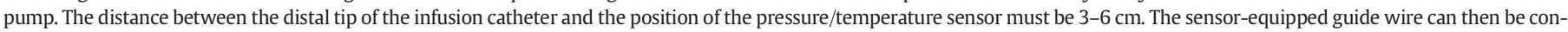

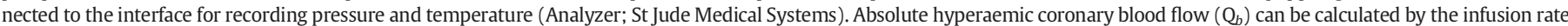
$\left(\mathrm{Q}_{i}\right)$, temperature of the infused saline $\left(\mathrm{T}_{i}\right)$ and distal blood temperature after complete mixing $(\mathrm{T})$. (See equation in text).

\subsection{Cardiovascular magnetic resonance (CMR)}

CMR was performed 3-5 days after the index procedure, preferably on the same day as the second invasive procedure. CMR was performed on either of two 1.5 T systems: Siemens or Magnetom Vision. Cine images were acquired on a 1.5 T scanner (Ingenia CV, Release 4.1.3.0 Philips Medical Systems, Best, The Netherlands) with electrocardiographic gating.

All subjects were placed in a supine position and short-axis, fourchamber, two-chamber and 3-chamber views were acquired during an end expiratory breath hold. Left ventricular function was assessed by a standard steady-state free precession technique (repetition time $3.3 \mathrm{~ms}$, echo time $70 \mathrm{~ms}$, flip angle 60 degrees, slice thickness $8 \mathrm{~mm}$, slice gap $0 \mathrm{~mm}$ ). An example of a mid LV short-axis image is shown in Fig. 3.

For determination of the area at risk, we obtained short-axis slices covering the whole ventricle using a T2-weighted triple inversion recovery breath-hold pulse sequence (repetition time $2000 \mathrm{~ms}$, echo time $70 \mathrm{~ms}$, flip angle 90 degrees, slice thickness $8 \mathrm{~mm}$, slice gap $0 \mathrm{~mm}$ ).

All CMR images were analyzed using the freely available software Segment v 1.8 http://segment.heiberg.se (Heiberg et al. Bmc med imaging 10: 1, 2010).

The left ventricular (LV) mass was assessed on the cine images by manual tracing of the endocardial and epicardial borders with exclusion of the papillary muscles.
The AR was derived from the T2-weighted imaging and defined as the total amount of hyperintensive myocardium in all short-axis slices and expressed as a percentage of LV mass. All endocardial and epicardial tracings were performed by two observers blinded to the clinical data. They had to agree and provide the final percentage of the area at risk. Offline recalculation was done to obtain the AR and LV mass in grams.

\subsection{Statistical analysis}

Data are presented as mean \pm standard deviation (SD), or median and interquartile range (IQR), as appropriate. Flow was expressed as $\mathrm{ml} / \mathrm{min} / \mathrm{g}$. Resistance was expressed as dyne.sec.cm-5/g. IMR was expressed as dimensionless index (arbitrary units). Due to the maximal vasodilated state of the coronary circulation, a linear relationship was assumed to exist between perfusion pressure and blood flow [13]. To compare the multiple measurements of flow over time within the same patient at different perfusion pressures, pressures were normalized to the initial aortic pressure $\left(\mathrm{P}_{\mathrm{a}}\right)$ as proposed by Fearon et al. [8]. IMR values at the initial measurement in the hyperacute phase of STEMI were divided in two groups, high and low, separated by the median value.

For evaluation of absolute flow and resistance over time within the same patient, each patient was his own control after normalization for aortic pressure. For comparison of flow and resistance between different patients, AR by CMR was used to calculate flow in $\mathrm{ml} / \mathrm{min} / \mathrm{g}$ of tissue, 


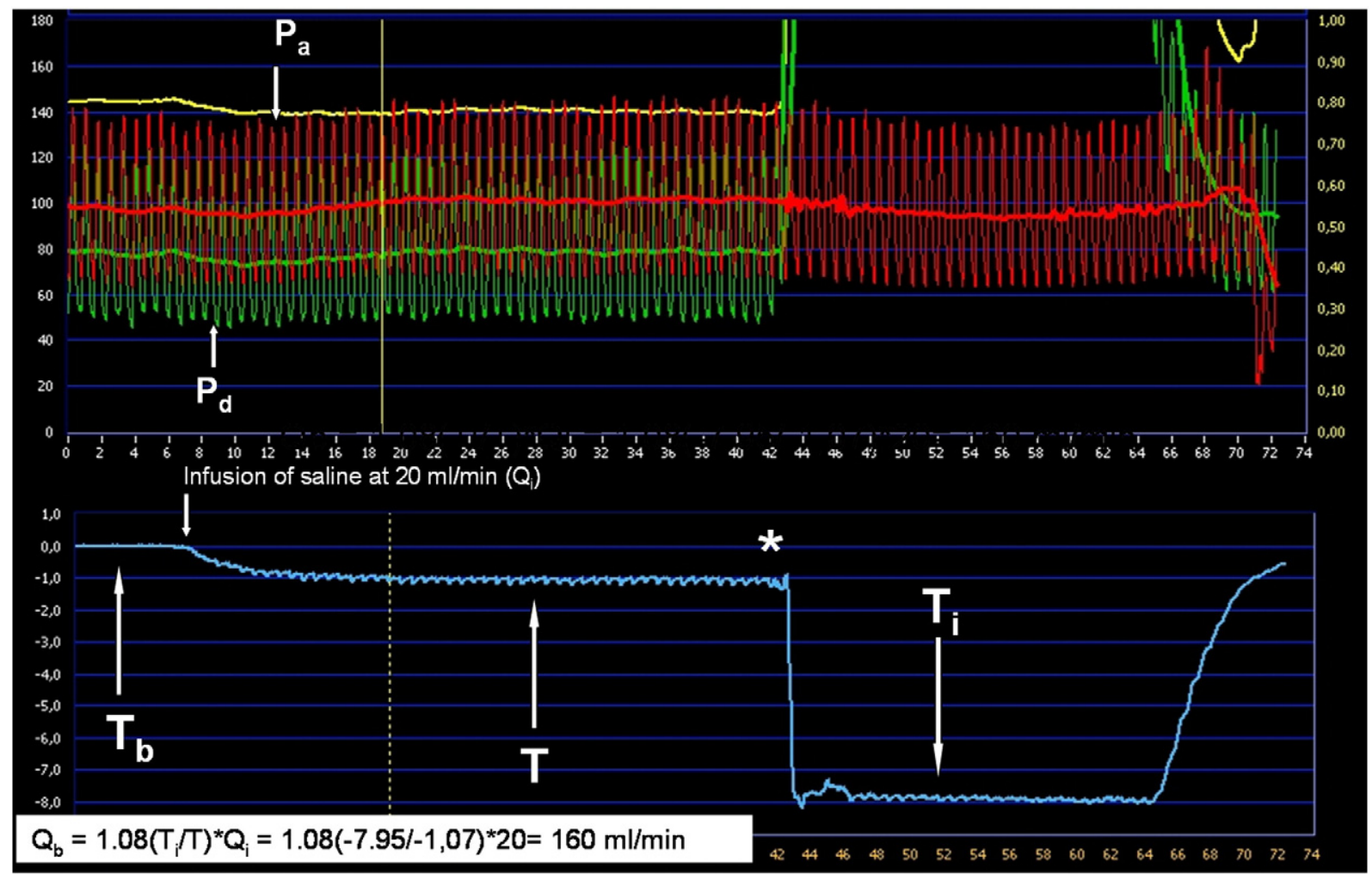

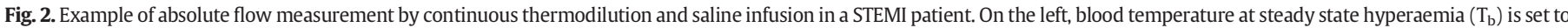

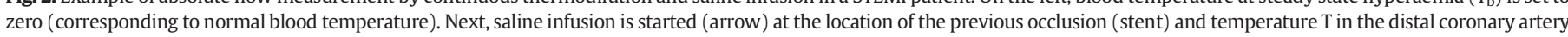

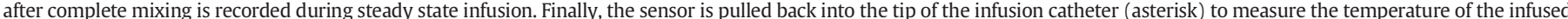

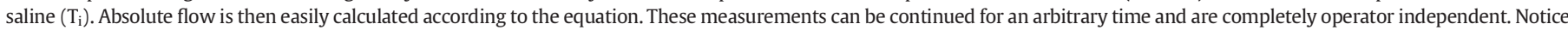

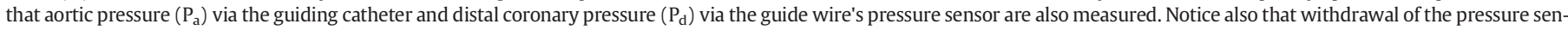
sor into the infusion catheter is marked by the sudden increase of the pressure signal.

by dividing absolute flow and resistance by the mass of the AR. Differences between groups were assessed by the paired t-test for continuous data with a normal distribution. Otherwise, the nonparametric Wilcoxon rank-sum test was used.

\section{Results}

Twenty patients enrolled in the study. Five patients withdrew informed consent after the first procedure. Consequently, flow and resistance data were available for 20 patients in the acute phase of STEMI and in 15 patients after 3-5 days. CMR was available in 16 patients. In one patient all invasive measurements were performed successfully, but it was not possible to analyze the CMR images accurately because of low image quality and, therefore, flow could not be related to the AR in that patient.

Baseline clinical and angiographic characteristics are presented in Table 1 . The left anterior descending artery was the culprit vessel in 8 cases, the right coronary artery in 8 cases, and the left circumflex artery in 4 cases. In 8 patients, the culprit vessel was not totally occluded at presentation. After PPCI, TIMI 3 flow was achieved in all cases.

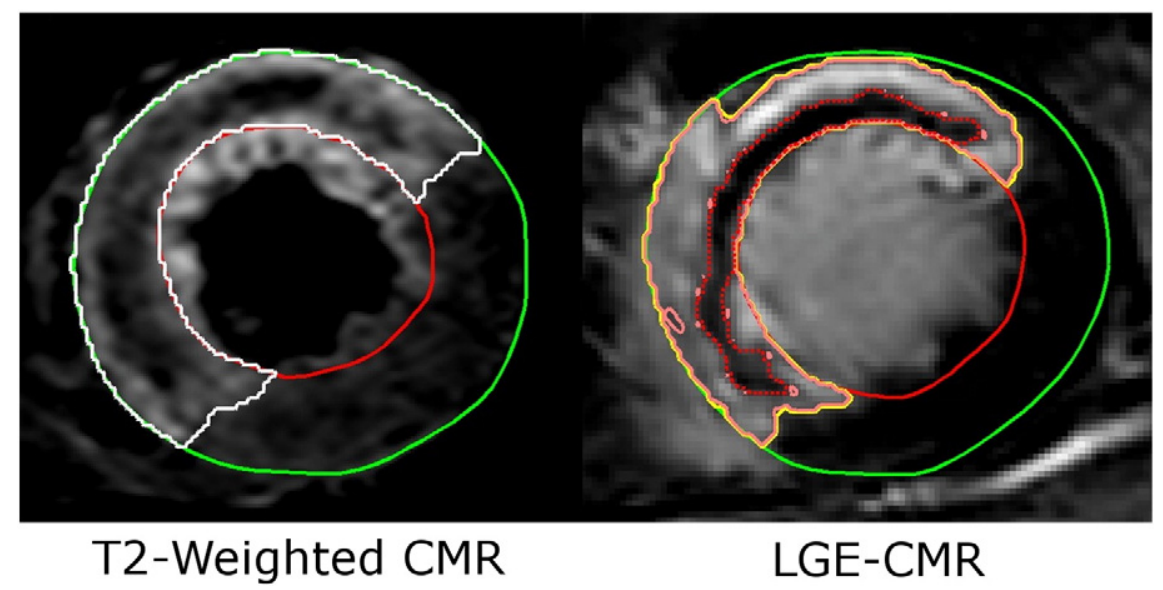

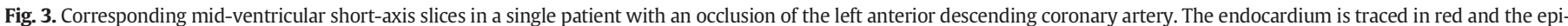

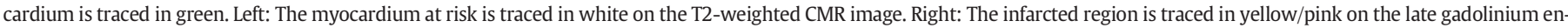

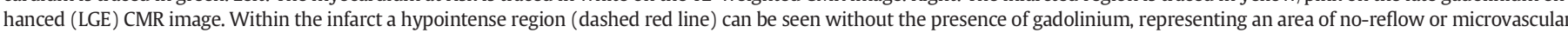
obstruction. 
Table 1

Clinical and angiographic characteristics at baseline.

\begin{tabular}{llll}
\hline Variable & $\mathrm{n}$ & $=$ & 20 \\
\hline Age, yrs & 57 & \pm & 9 \\
Male & 16 & & $(80 \%)$ \\
Risk factors & & & $(10 \%)$ \\
Diabetes & 2 & & $(15 \%)$ \\
Hypertension & 3 & & $(20 \%)$ \\
Hyperlipidemia & 4 & & $(45 \%)$ \\
Family history of CAD/PAD & 9 & & \\
Smoking & 14 & & \\
Onset symptoms -reperfusion & 162 & & $(40 \%)$ \\
(min) & & & $(40 \%)$ \\
Localization culprit lesion & & & $(20 \%)$ \\
LAD & 8 & & 0.4 \\
RCA & 8 & & \\
CX & 4 & & \\
Reference diameter culprit vessel (mm) & 3.4 & & \\
\hline
\end{tabular}

Measurements of invasive and CMR indices are shown in Table 2. Measuring FFR in the acute phase does not make any sense, but FFR in the subacute phase showed that epicardial revascularization had been successful in all patients. A saline infusion rate of $20 \mathrm{ml} / \mathrm{min}$ was used except in patients number 17 and 18, in whom 30 and $25 \mathrm{ml} / \mathrm{min}$ was used, respectively, because of the large diameter of the culprit artery. All measurements related to this protocol were completed within $25 \mathrm{~min}$. In one patient in whom the RCA was the culprit artery, brief, transient second-degree AV block occurred without hemodynamic consequence. No other complication occurred due to the invasive measurements either in the hyperacute phase or in the subacute phase. Fig. 4 shows the changes in absolute coronary blood flow in the AR over time. In healthy individuals, maximum absolute blood flow equals 3.7-6.5 $\mathrm{ml} / \mathrm{min} / \mathrm{g}$ [14]. In our study, average hyperaemic blood flow to the AR was $3.14 \pm 1.64 \mathrm{ml} / \mathrm{min} / \mathrm{g}$ in the hyperacute phase and $3.68 \pm 1.93 \mathrm{ml} / \mathrm{min} / \mathrm{g}$ after $3-5$ days $(p=0.25)$. Some patients showed a remarkable increase in coronary blood flow over time, whereas in others coronary blood flow did not change or even became slightly lower.

Absolute resistance in the hyperacute phase could be calculated for all patients and varied from 21,789 to 160,000 dyne.sec.cm-5. Average absolute resistance in the AR decreased from 1317 dyne.sec.cm-5/g in the hyperacute phase to 1099 dyne.sec.cm-5/g after 3-5 days ( $p=$ 0.40; Fig. 4). A high IMR directly after PPCI was associated with a lower absolute flow to the area at risk, whereas low IMR was associated with an almost normal myocardial flow ( $p=0,15$; Fig. 5).

\section{Discussion}

This study performed the first absolute coronary flow measurements in acute STEMI patients using the technique of thermodilution with continuous infusion of saline. Repeat measurements in the same coronary artery were performed after a time interval of several days. We showed that measurement of absolute coronary blood flow is safe and feasible in STEMI patients.

The interpretation of absolute flow in the infarcted area is not trivial. First, the measured value should be related to the AR, for which a cardiac magnetic resonance imaging exam within a few days is mandatory. Second, absence of change between the hyperacute and subacute phase can indicate either minimal initial damage as a result of effective and timely PPCI, or extensive damage without recovery. By relating flow to mass, those two different states can be distinguished. An increase in absolute maximum flow between the hyperacute and subacute phase most likely indicates recovery, as it reflects the decrease of minimal microvascular resistance in the AR.

Currently the invasive index typically used to characterize qualitative microvascular (dys)function in STEMI is the index of microvascular resistance (IMR). In our study, a clear correlation was found between IMR and absolute flow in the hyperacute phase (Fig. 5).
The median IMR of 22 in our study is lower than in the study by Fearon et al., where the median IMR was 32 [8]. This difference could be explained by a shorter "onset-of-pain to balloon time" in our study (mean $287 \pm 138$ versus $162 \pm 122 \mathrm{~min}$ ).

IMR measurement in STEMI patients offers the opportunity to identify inadequate myocardial reperfusion after PPCI, but is limited by its operator dependency and relatively high variability. Because the technique of measuring absolute blood flow as in this study allows repeated measurements over time with little variation and is fully operator independent, we expect that absolute flow measurement in the infarct related artery is a potentially more reliable tool to evaluate the effect of therapy over time within one individual patient. Nevertheless, interpretation of absolute coronary flow as a single value still remains difficult due to large interindividual variability related to the AR. A relatively high flow could be normal in one patient if the dependent perfusion territory is small, but low for another patient with a large perfusion territory. For these reasons, in contrast to IMR, estimation of myocardial mass by CMR is necessary to interpret absolute flow in a useful way. In addition, a potential limitation of this methodology could be the volume load associated with these measurements. In our study, however, infused volume was rather modest (flow rate $\leq 30 \mathrm{ml} / \mathrm{min}$ and total infusion ${ }^{\ulcorner} 200 \mathrm{ml}$ in all patients) and not expected to give clinical problems. Lack of measurement in a control artery is not a real limitation because the IRA serves as its own control. Finally, although this technique is not difficult, instrumentation is not trivial and a special infusion catheter and software (St Jude Medical) is necessary. For these reasons this technique will be limited to research purposes for the present time, in contrast to IMR.

\subsection{Study limitations}

This was a small study in only 20 selected patients, and larger data series are needed to explore further the therapeutic consequences of measuring absolute coronary blood flow. Potential future studies could use it to identify high-risk patients, monitor the effect of drugs administered during PPCI such as glycoprotein IIB/IIIAinhibitors or nitroglycerine, or better evaluate the effect of an intra-aortic balloon pump.

\section{Conclusion}

The technique of thermodilution using a modest, continuous, intracoronary infusion of saline permits safe and feasible measurement of absolute coronary blood flow and microvascular resistance during PPCI in STEMI patients. This technique may allow better exploration and understanding of microvascular (dys)function in the early phase of STEMI. Absolute blood flow per gram of tissue of myocardium at risk correlates well with IMR. During the first couple of days absolute flow increases and resistance decreases in a considerable number of patients, indicating recovery of microvascular dysfunction over time. Larger studies are mandatory to evaluate the clinical consequences of these kinds of measurements.

\section{Funding Sources}

This study was supported by a grant of the Friends of the Heart Foundation (Stichting Vrienden van het Hart) in Eindhoven, The Netherlands.

\section{Disclosures}

Dr. Pijls received institutional research grants from St Jude Medical and is consultant to St Jude Medical. 
Table 2

Hemodynamic and CMR measurements.

\begin{tabular}{|c|c|c|c|c|c|c|c|c|c|c|c|c|c|c|c|c|c|c|}
\hline No & TIMIpre & $\begin{array}{l}\text { AR } \\
(\mathrm{g})\end{array}$ & $\begin{array}{l}\text { LVmass } \\
(\mathrm{g})\end{array}$ & $\begin{array}{l}\text { AR/LV } \\
\text { mass (\%) }\end{array}$ & IMRO & IMRFU & $\begin{array}{l}\mathrm{Q} 0 \\
(\mathrm{ml} / \mathrm{min})\end{array}$ & $\begin{array}{l}\text { QFU } \\
(\mathrm{ml} / \mathrm{min})\end{array}$ & $\begin{array}{l}\mathrm{QAR}, 0 \\
(\mathrm{ml} / \mathrm{min} / \mathrm{g})\end{array}$ & $\begin{array}{l}\text { QAR,FU } \\
(\mathrm{ml} / \mathrm{min} / \mathrm{g})\end{array}$ & $\begin{array}{l}\triangle \mathrm{QAR} \\
(\%)\end{array}$ & $\begin{array}{l}\text { R0 } \\
\text { (dyne.sec.cm- } \\
\text { 5) }\end{array}$ & $\begin{array}{l}\text { RFU } \\
\text { (dyne.sec.cm- } \\
\text { 5) }\end{array}$ & $\begin{array}{l}\text { R0,AR } \\
\text { (dyne.sec.cm-5)/ } \\
\text { g }\end{array}$ & $\begin{array}{l}\text { RFU,AR } \\
\text { (dyne.sec.cm-5)/g }\end{array}$ & FFRFU & $\begin{array}{l}\mathrm{R}_{\mathrm{FU}, \mathrm{AR}} \\
(\text { dyne.sec.cm } \\
\mathrm{g}\end{array}$ & $\mathrm{FFR}_{\mathrm{FU}}$ \\
\hline 1 & 0 & 33 & 121 & $27 \%$ & 60 & 14 & 34 & 173 & 1,05 & 5,29 & $407 \%$ & 160,000 & 34,444 & 4893 & 1053 & 0,95 & 1053 & 0,95 \\
\hline 2 & 0 & 33 & 102 & $32 \%$ & 15 & 37 & 120 & 106 & 3,68 & 3,26 & $-11 \%$ & 37,377 & 39,273 & 1147 & 1205 & 0,98 & 1205 & 0,98 \\
\hline 3 & 2 & - & - & - & 18 & 31 & 225 & 186 & - & - & - & 26,544 & 22,919 & - & - & 0,88 & - & 0,88 \\
\hline 4 & 0 & 45 & 142 & $32 \%$ & 33 & 27 & 171 & 232 & 3,76 & 5,11 & $36 \%$ & 32,093 & 27,208 & 707 & 599 & 0,98 & 599 & 0,98 \\
\hline 5 & 0 & 22 & 110 & $20 \%$ & 52 & 14 & 96 & 143 & 4,38 & 6,52 & $49 \%$ & 55,758 & 40,795 & 2534 & 1854 & 0,85 & 1854 & 0,85 \\
\hline 6 & 0 & - & - & - & 31 & - & 143 & - & - & - & - & 43,590 & - & - & - & - & - & - \\
\hline 7 & 0 & 52 & 106 & $49 \%$ & 11 & 18 & 44 & 111 & 0,85 & 2,13 & $151 \%$ & 127,347 & 53,543 & 2454 & 1032 & 0,95 & 1032 & 0,95 \\
\hline 8 & 3 & 54 & 198 & $27 \%$ & 16 & 12 & 174 & 171 & 3,26 & 3,19 & $-2 \%$ & 28,571 & 31,678 & 534 & 592 & 0,96 & 592 & 0,96 \\
\hline 9 & 0 & 56 & 140 & $40 \%$ & 68 & 10 & 86 & 80 & 1,53 & 1,44 & $-6 \%$ & 48,352 & 49,032 & 863 & 876 & 0,96 & 876 & 0,96 \\
\hline 10 & 0 & 31 & 140 & $22 \%$ & 11 & 16 & 168 & 148 & 5,45 & 4,81 & $-12 \%$ & 23,902 & 30,330 & 776 & 985 & 0,9 & 985 & 0,9 \\
\hline 11 & 0 & 26 & 145 & $18 \%$ & 22 & 14 & 157 & 182 & 6,03 & 6,99 & $16 \%$ & 33,121 & 30,870 & 1269 & 1183 & 0,97 & 1183 & 0,97 \\
\hline 12 & 3 & - & - & - & 9 & - & 102 & - & - & - & - & 48,762 & - & - & - & - & - & - \\
\hline 13 & 2 & 48 & 101 & $47 \%$ & 16 & 21 & 149 & 158 & 3,13 & 3,33 & $6 \%$ & 48,312 & 35,789 & 1017 & 753 & 0,82 & 753 & 0,82 \\
\hline 14 & 3 & 101 & 151 & $67 \%$ & 23 & 13 & 199 & 96 & 1,96 & 0,95 & $-52 \%$ & 31,414 & 59,592 & 310 & 589 & 0,83 & 589 & 0,83 \\
\hline 15 & 0 & 27 & 156 & $17 \%$ & 15 & 32 & 98 & 46 & 3,70 & 1,73 & $-53 \%$ & 39,588 & 100,984 & 1494 & 3811 & 0,99 & 3811 & 0,99 \\
\hline 16 & 0 & 50 & 135 & $37 \%$ & 50 & - & 118 & - & 2,35 & - & - & 31,736 & - & 635 & - & - & - & - \\
\hline 17 & 1 & 97 & 220 & $44 \%$ & 65 & 61 & 103 & 194 & 1,07 & 2,00 & $88 \%$ & 54,154 & 28,980 & 559 & 299 & 0,86 & 299 & 0,86 \\
\hline 18 & 2 & 53 & 157 & $34 \%$ & 20 & 21 & 258 & 255 & 4,83 & 4,78 & $-1 \%$ & 29,921 & 29,395 & 560 & 550 & 0,91 & 550 & 0,91 \\
\hline 19 & 2 & - & - & - & 36 & - & 251 & - & - & - & - & 21,789 & - & - & - & - & - & - \\
\hline 20 & 0 & - & - & - & 85 & - & 76 & - & - & - & - & 53,684 & - & - & - & - & - & - \\
\hline
\end{tabular}

0 indicates time of infarction.

FU indicates 3-5 days after infarction (follow-up).

$\mathrm{FFR}=$ fractional flow reserve

IMR $=$ index of microvascular resistance

$\mathrm{AR}=$ area at risk.

LV mass $=$ left ventricular mass

$\mathrm{Q}=$ absolute coronary blood flow $(\mathrm{ml} / \mathrm{min})$.

$\mathrm{QAR}=$ absolute coronary blood flow corrected for area at risk ( $\mathrm{ml} / \mathrm{min} / \mathrm{g})$.

$\mathrm{R}=$ absolute minimal resistance (dyne.sec.cm-5).

$\mathrm{RAR}=$ absolute minimal resistance corrected for area at risk (dyne.sec.cm-5)/g. 


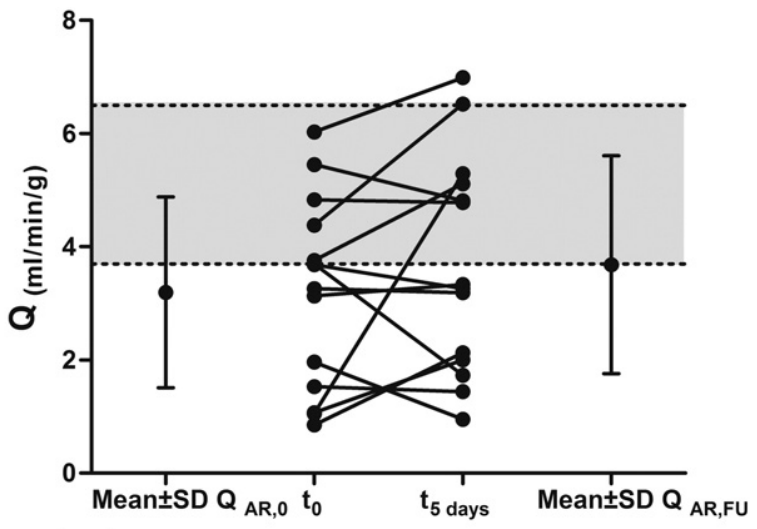

a

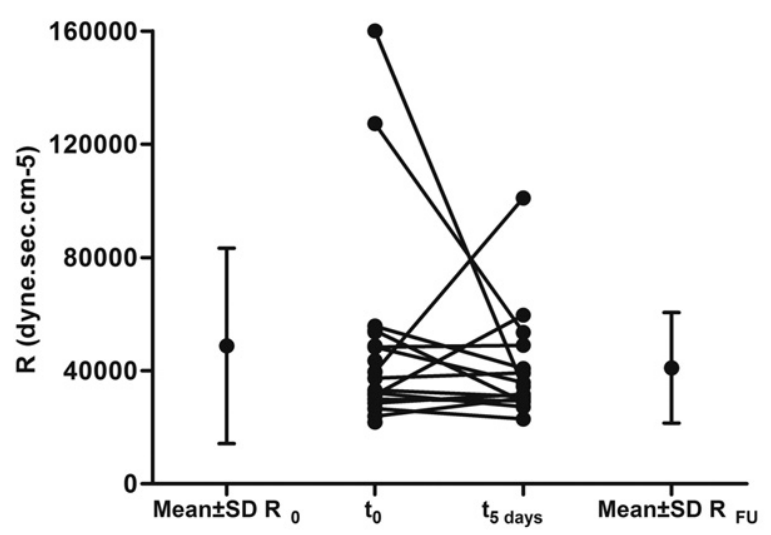

b

Fig. 4. Absolute coronary blood flow to the area at risk at the time of infarction immediately after $\mathrm{PPCI}\left(\mathrm{t}_{0}\right)$, and $3-5$ days post-infarction $\left(\mathrm{t}_{5}\right)$. The shadowed area indicates the range of normal maximum myocardial blood flow in healthy persons (upper panel). The lower panel shows the absolute minimal resistance at the time of infarction and after 3-5 days.

\section{Acknowledgments}

The authors gratefully acknowledge the assistance and patience of the catheterization laboratory nurses of the Catharina Hospital in performing these experiments.

\section{References}

[1] Keeley EC, Boura JA, Grines CL. Primary angioplasty versus intravenous thrombolytic therapy for acute myocardial infarction: a quantitative review of 23 randomised trials. Lancet 2003;361:13-20.

[2] Gibson CM, Cannon CP, Murphy SA, Marble SJ, Barron HV, Braunwald E, et al. Relationship of the TIMI myocardial perfusion grades, flow grades, frame count, and per-

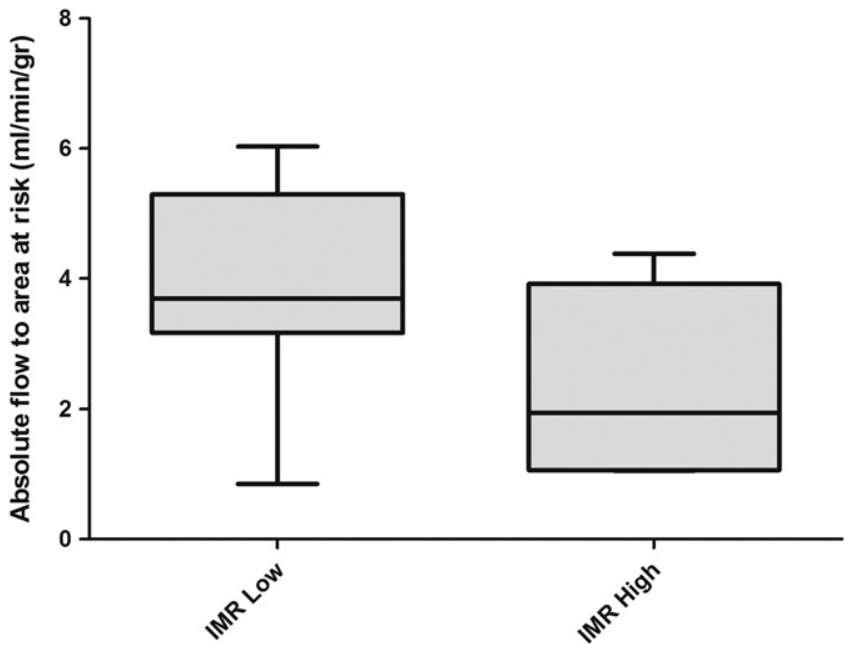

Fig. 5. Box and whisker plots for absolute flow corrected for the area at risk (AR) according to high and low index of microvascular resistance (IMR). The box limits represent the 10 th and 90th percentiles. The horizontal line within the box represents the median value.

cutaneous coronary intervention to long-term outcomes after thrombolytic administration in acute myocardial infarction. Circulation 2002;105:1909-13.

[3] Rochitte CE, Lima JA, Bluemke DA, Reeder SB, McVeigh ER, Furuta T, et al. Magnitude and time course of microvascular obstruction and tissue injury after acute myocardial infarction. Circulation 1998;98:1006-14.

[4] Roe MT, Ohman EM, Maas AC, Christenson RH, Mahaffey KW, Granger CB, et al. Shifting the open-artery hypothesis downstream: the quest for optimal reperfusion. I Am Coll Cardiol 2001;37:9-18.

[5] Lepper W, Hoffmann R, Kamp O, Franke A, de Cock CC, Kuhl HP, et al. Assessment of myocardial reperfusion by intravenous myocardial contrast echocardiography and coronary flow reserve after primary percutaneous transluminal coronary angioplasty [correction of angiography] in patients with acute myocardial infarction. Circulation 2000;101:2368-74.

[6] Yellon DM, Hausenloy DJ. Myocardial reperfusion injury. N Engl J Med 2007;357: 1121-35.

[7] Kloner RA, Ganote CE, Jennings RB. The "no-reflow" phenomenon after temporary coronary occlusion in the dog. J Clin Invest 1974; 54:1496-508.

[8] Fearon WF, Shah M, Ng M, Brinton T, Wilson A, Tremmel JA, et al. Predictive value of the index of microcirculatory resistance in patients with ST-segment elevation myocardial infarction. J Am Coll Cardiol 2008;51:560-5.

[9] Aarnoudse W, Van't Veer M, Pijls NH, TerWoorst J, Vercauteren S, Tonino P, et al. Direct volumetric blood flow measurement in coronary arteries by thermodilution. $J$ Am Coll Cardiol 2007;50:2294-304.

[10] Otterspoor LC, van't V M, van Nunen LX, Wijnbergen I, Tonino PA, Pijls NH. Safety and feasibility of local myocardial hypothermia. Catheter Cardiovasc Interv 2015:13.

[11] Doucette JW, Corl PD, Payne HM, Flynn AE, Goto M, Nassi M, et al. Validation of a Doppler guide wire for intravascular measurement of coronary artery flow velocity. Circulation 1992;85:1899-911.

[12] Fearon WF, Balsam LB, Farouque HM, Caffarelli AD, Robbins RC, Fitzgerald PJ, et al. Novel index for invasively assessing the coronary microcirculation. Circulation 2003;107:3129-32.

[13] Pijls NH, van Son JA, Kirkeeide RL, DeBruyne B, Gould KL. Experimental basis of determining maximum coronary, myocardial, and collateral blood flow by pressure measurements for assessing functional stenosis severity before and after percutaneous transluminal coronary angioplasty. Circulation 1993;87:1354-67.

[14] Camici P. Ferrannini E, Opie LH. Myocardial metabolism in ischemic heart disease: basic principles and application to imaging by positron emission tomography. Prog Cardiovasc Dis 1989;32:217-38. 